\title{
HUBUNGAN POLA KONSUMSI PANGAN SUMBER SERAT DENGAN KEJADIAN OVERWEIGHT PADA REMAJA DI SMP NEGERI 3 MAKASSAR
}

\section{RELATIONSHIP OF FIBER SOURCE FOOD CONSUMPTION PATTERN WITH THE INCIDENCE OF OVERWEIGHT IN ADOLESCENTS AT SMPN 3 MAKASSAR}

\author{
Anggun Dwi Harti ${ }^{1}$, Rahayu Indriasari ${ }^{1}$, Healthy Hidayanti ${ }^{1}$
}

(Email/Hp: anggundwi0240@gmail.com/085770345969)

${ }^{1}$ Program Studi Ilmu Gizi, Fakultas Kesehatan Masyarakat, Univesitas Hasanuddin, Makassar

\begin{abstract}
ABSTRAK
Pendahuluan: Sayur dan buah-buahan ini diperlukan oleh manusia karena kandungan seratnya atau fiber yang berperan terhadap overweight diantaranya menunda pengosongan lambung, mengurangi rasa lapar, pencernaan dan dapat mengurangi terjadinya overweight. Remaja usia 13-15 tahun memiliki konsumsi buah dan sayur lebih rendah dibanding anak usia 5-10 tahun dan usia 16 tahun ke atas. Tujuan: Tujuan penelitian ini adalah ntuk mengetahui hubungan konsumsi pangan sumber serat dengan kejadian overweight pada remaja di SMP Negeri 3 Makassar. Metode: Desain penelitian ini adalah analitik dengan desain crosssectional dan pengambilan sampel proportional sampling. Populasi pada penelitian ini sebanyak 792 siswa kelas VII dan kelas VII. Sampel sebanyak 93 siswa dengan status gizi overweight dan normal yang diperoleh dari screening antropometri. Kemudian dilakukan wawancara FFQ Semikuantitatif (SQ-FFQ) untuk dapat mengetahui jumlah dan frekuensi konsumsi pangan sumber serat. Analisis data pada penelitian ini menggunakan uji chi-square dan Fisher Exact Test. Hasil: Didapatkan hasil pada frekuensi konsumsi pangan sumber serat nilai $p$-value sebesar 1,000. Lalu jumlah konsumsi pangan sumber serat nilai $p$ value sebesar 0,819. Kesimpulan: Dapat disimpulkan bahwa tidak ada hubungan antara pola konsumsi pangan sumber serat dengan kejadian overweright pada remaja di SMP Negeri 3 Makassar.
\end{abstract}

Kata kunci : Serat, Overweight, dan Remaja

\section{ABSTRACT}

Introduction: Vegetables and fruits are needed by humans because the fiber content or fiber that plays a role in overweight includes delaying gastric emptying, reducing hunger, digestion and can reduce the occurrence of overweight. Teens aged 13-15 years have lower consumption of fruit and vegetables than children aged 5-10 years and ages 16 years and over. Objective: The purpose of the study was to determine the relationship of fiber source food consumption with the incidence of overweight in adolescents in SMPN 3 Makassar. Methods: The design of this study was analytic with cross-sectional design and purposive sampling. The population in this study were 792 students of class VII and class VII. 
A sample of 93 students with overweight and normal nutritional status were obtained from anthropometric screening. Then a semiquantitative $F F Q$ interview $(S Q-F F Q$ ) was conducted to determine the amount and frequency of fiber source food consumption. Results: analysis of data in this study using the chi-square test. Obtained results on frequency of fiber source food consumption $p$ value 1,000. Then the amount of fiber source food consumption is $p$ value 0.819.Conclusions: The concluded that there is no relationship between fiber-source food consumption patterns and the occurrence of overweright in adolescents in SMPN 3 Makassar.

\section{Keywords : Fiber, Overweight, and Adolescent}

\section{PENDAHULUAN}

Konsumsi sayur dan buah sangat penting dalam kehidupan sehari-hari karena berfungsi sebagai zat pengatur, mengandung zat gizi seperti vitamin dan mineral, memiliki kadar air tinggi, sumber sarat makanan, antioksidan dan dapat mencegah terjadinya berbagai penyakit degeneratif seperti obesitas, (penyakit jantung koroner) PJK, diabetes, hipertensi, dan kanker. ${ }^{1}$ Sayur dan buah-buahan ini diperlukan oleh manusia karena kandungan seratnya atau fiber. Serat ini merupakan komponen jaringan yang pada tanaman yang tidak dapat dicerna oleh enzim pencernaan. Artinya tidak ada enzim pencernaan yang mampu mengurai serat menjadi komponen yang mudah diserap. Keadaan ini memberi keuntungan bagi manusia terutama untuk. ${ }^{2}$

Apabila terjadi kekurangan dalam mengonsumsi buah dan sayur akan menyebabkan tubuh kekurangan nutrisi seperti vitamin, mineral, serat dan tidak seimbangnya asam basa tubuh, sehingga dapat mengakibatkan timbulnya berbagai penyakit. Kekurangan konsumsi sayur dan buah pada anak dapat menimbulkan berbagai penyakit di kemudian hari. Rendahnya konsumsi sayur dan buah ini berkaitan dengan meningkatnya risiko 2 terjadinya penyakit-penyakit kronik seperti penyakit jantung dan diabetes. ${ }^{3}$ Hasil penelitian Lock et al. (2005) yang dilakukan di beberapa negara bagian Afrika, Amerika, dan Asia yang terdiri atas 14 wilayah bagian menyebutkan bahwa anak usia 5-14 tahun memiliki kecenderungan 20\% mengonsumsi buah dan sayur lebih rendah bila dibandingkan dengan orang dewasa 30-59 tahun. Rata-rata konsumsi buah dan sayur pada anak usia 5-14 tahun di Asia Tenggara memperlihatkan hasil yang sangat rendah yaitu $182 \mathrm{~g} /$ hari. Hasil tersebut berbeda jauh dengan rekomendasi yang dikeluarkan oleh WHO, bahwa konsumsi buah dan sayur adalah $400 \mathrm{~g}$ (5 porsi) per hari untuk semua kelompok usia. ${ }^{4}$

Berdasarkan Riset Kesehatan Dasar (Riskesdas) tahun 2018 proporsi konsumsi buah dan sayur kurang dari 5 porsi per hari pada penduduk umur $\geq 5$ tahun menurut provinsi pada tahun 2018 yaitu di Indonesia mencapai 95,5\%. Persentase kurang konsumsi buah dan sayur meningkat dari tahun 2013 hingga 2018 yaitu 93,5\% menjadi 95,5\%. Provinsi Sulawesi Selatan tahun 2007 dan 2013 mengumpulkan data yang sama yaitu melakukan analisis kecenderungan proporsi penduduk umur $\geq 10$ tahun yang mengonsumsi kurang sayur dan buah. Dari data Riskesdas 2013 ditemukan bahwa perubahan yang paling menonjol terjadi di Gorontalo, dengan proporsi kurang konsumsi sayur dan buah semakin meningkat dari 83,5\% menjadi 92,5\%, demikian juga dengan provinsi Sulawesi Selatan yang mengalami peningkatan dari 93,7\% menjadi sekitar $96 \%$. 
Kelebihan berat badan (overweight) telah menjadi trend masalah gizi dikelompok siswa Sekolah Menengah Pertama (SMP) dan merupakan masalah gizi masyarakat yang berdampak pada morbiditas dan mortalitas. Berdasarkan Riskesdas 2013, Indeks massa tubuh menurut umur (IMT/U) prevalensi remaja gemuk umur 13-15 tahun di Indonesia sebesar $10.8 \%$ terdiri dari $8,3 \%$ gemuk dan $2,5 \%$ sangat gemuk. yang tertinggi yaitu pada provinsi kepulauan riau sebesar $0,6 \%$, provinsi DKI sebesar 0,5\%, prevalensi obesitas di Provinsi kalimantan timur dan Provinsi DIY sebesar 0,3\% sedangkan prevalensi obesitas Di Provinsi Sulawesi Utara dan di Provinsi Sulawesi Selatan sebesar 0,2\%. ${ }^{5}$ Faktor utama penyebab overweight dan obesitas adalah aktivitas fisik yang kurang, perubahan gaya hidup, serta pola makan yang salah diantaranya pola makan tinggi lemak dan rendah serat. Faktor utama penyebab overweight dan obesitas adalah aktivitas fisik yang kurang, perubahan gaya hidup, serta pola makan yang salah diantaranya pola makan tinggi lemak dan rendah serat. ${ }^{6}$

Berdasarkan uraian di atas, menunjukkan bahwa mayoritas penduduk memiliki perilaku kurang konsumsi buah dan sayur serta dengan melihat berbagai dampak yang ditimbulkan akibat kurang konsumsi buah dan sayur, maka dinilai perlu untuk mengetahui pengaruh konsumsi sayur dan buah dengan overweight. Penting untuk mengetahui pola konsumsi buah dan sayur pada remaja karena remaja memerlukan nutrisi dari buah dan sayur untuk pertumbuhannya. Maka dari itu, tujuan dari penelitian ini adalah untuk mengetahui hubungan pola konsumsi pangan sumber serat dengan kejadian overweight pada remaja SMP Negeri 3 Makassar.

\section{BAHAN DAN METODE}

Jenis penelitian yang digunakan adalah penelitian kuantitatif dan rancangan penelitian analitik dengan desain cross-sectional. Penelitian ini dilaksanakan di SMPN 3 Makassar pada bulan April-Mei 2019. Populasi penelitian ini adalah siswa-siswi kelas VII dan VIII SMPN 3 Makassar yang berjumlah 792 siswa. Kelas VII berjumlah 432 siswa dan kelas VIII berjumlah 360 siswa. Dalam satu kelas jumlah siswanya yaitu 36 orang. Jumlah sampel sebesar 93 siswa dengan status gizi overweight dan normal yang diambil setelah sebelumnya dilakukan screening antropometri sebanyak satu kali yaitu dengan cara melakukan pengukuran TB dan penimbangan BB. Alat yang digunakan yaitu timbangan dan microtoice. Metode pengambilan sampel dilakukan dengan menggunakan teknik proportional sampling. Jenis sampling ini adalah pengambilan sampel yang memperhatikan pertimbangan unsurunsur atau kategori dalam populasi penelitian.

Teknik pengumpulan data yaitu data primer yang berupa pengukuran fisik dan wawancara dengan responden menggunakan kuesioner FFQ Semikuantitatif (SQ-FFQ) dan data sekunder yaitu data diperoleh dari bagian kantor sekolah meliputi jumlah siswa, kelas, data sekolah, dan jumlah tenaga pengajar. Metode analisis data dilakukan dengan analisis univariate dan bivariate. Analisis univariate bertujuan untuk mendeskripsikan karakteristik setiap variabel penelitian, sedangkan Analisis bivariat bertujuan untuk menguji hipotesis hubungan variabel independen dengan variabel dependen yaitu konsumsi pangan sumber serat dengan overweight pada remaja. 


\section{HASIL}

Adapun hasil penelitian yang telah dilakukan terhadap siswa kelas VII dan VII yang menjadi sampel dalam penelitian ini, maka diperoleh hasil berdasarkan tabel menunjukkan bahwa $51(54,8 \%)$ sampel kelas VII dan 42 (45,2\%) sampel kelas VIII, diantaranya 34 $(36,6 \%)$ berjenis kelamin laki-laki dan $59(63,4 \%)$ berjenis kelamin perempuan. Berdasarkan umur sampel yang terbanyak adalah umur 14 tahun yaitu 88 (53\%) dan yang paling sedikit adalah umur 12 tahun yaitu $1(6 \%)$.

Tabel 1. Karakteristik Sampel

\begin{tabular}{|c|c|c|}
\hline \multirow[t]{2}{*}{ Karakteristik Umum } & \multicolumn{2}{|c|}{ Jumlah Responden } \\
\hline & $\mathbf{N}$ & $\%$ \\
\hline \multicolumn{3}{|l|}{ Kelas } \\
\hline VII & 51 & 54,8 \\
\hline VIII & 42 & 45,2 \\
\hline \multicolumn{3}{|l|}{ Jenis Kelamin } \\
\hline Laki-laki & 34 & 36,6 \\
\hline Perempuan & 59 & 63,4 \\
\hline \multicolumn{3}{|l|}{ Pekerjaan Ayah } \\
\hline Wiraswasta & 33 & 35,5 \\
\hline PNS & 19 & 20,4 \\
\hline Pegawai Swasta & 12 & 12,9 \\
\hline Dosen/Guru & 2 & 2,2 \\
\hline TNI/Polri & 10 & 10,8 \\
\hline Pengusaha & 4 & 4,3 \\
\hline Buruh Harian & 7 & 7,5 \\
\hline Petugas Kebersihan & 2 & 2,2 \\
\hline Pelayaran & 1 & 1,1 \\
\hline Tidak Ada & 3 & 3,2 \\
\hline \multicolumn{3}{|l|}{ Pekerjaan Ibu } \\
\hline IRT & 66 & 71 \\
\hline Wiraswasta & 8 & 8,6 \\
\hline Guru & 5 & 5,4 \\
\hline Pegawai Swasta & 2 & 2,2 \\
\hline PNS & 8 & 8,6 \\
\hline Pengusaha & 3 & 3,2 \\
\hline TNI & 1 & 1,1 \\
\hline Total & 166 & 100 \\
\hline
\end{tabular}

Sumber: Data primer, 2019.

Berdasarkan tabel dari karakteristik pekerjaan orang tua sampel menunjukkan bahwa pekerjaan Ayah terbanyak adalah sebagai Wiraswasta yaitu 33 (35,5\%) dan pekerjaan Ibu terbanyak adalah sebagai IRT yaitu 66 (71\%). Berdasarkan tabel 2, dapat diketahui bahwa jumlah responden yang memiliki jumlah porsi konsumsi pangan sumber serat cukup sebanyak $54(58,1 \%)$ dan kurang sebanyak $39(41,9 \%)$. Berdasarkan frekuensi konsumsi pangan 
sumber serat yang cukup sebanyak 2 (2,2\%) dan kurang sebanyak 91 (97,8\%). Dapat diketahui juga bahwa sampel yang memiliki status gizi overweight sebanyak 27 (29\%) dan status gizi normal sebanyak $66(71 \%)$.

Tabel 2. Hubungan Frekuensi Konsumsi Pangan Sumber Serat dengan Kejadian Overweight

\begin{tabular}{|c|c|c|c|c|c|c|c|}
\hline \multirow{2}{*}{$\begin{array}{c}\text { Frekuensi } \\
\text { Konsumsi } \\
\text { Pangan } \\
\text { Sumber Serat }\end{array}$} & \multicolumn{4}{|c|}{ Status Gizi } & \multicolumn{2}{|c|}{ Jumlah } & \multirow{2}{*}{$\mathbf{p}^{*}$} \\
\hline & Overweight & $\%$ & Normal & $\%$ & $\mathbf{N}$ & $\%$ & \\
\hline Kurang & 27 & 29,7 & 64 & 70,3 & 91 & 100 & \multirow{3}{*}{1,000} \\
\hline \multirow[t]{2}{*}{ Cukup } & 0 & 0 & 2 & 100 & 2 & 100 & \\
\hline & 27 & 29 & 66 & 71 & 93 & 100 & \\
\hline
\end{tabular}

Sumber: Data primer, 2019

Berdasarkan tabel 2, menunjukkan bahwa lebih banyak sampel yang memiliki status gizi overweight dengan frekuensi konsumsi pangan sumber serat kurang yaitu 27 orang $(29,1 \%)$ dibanding yang memiliki frekuensi konsumsi pangan sumber serat cukup. Pada penelitian ini hasil analisis uji chi square menunjukkan tabel kontigensi 2 × 2 tidak memenuhi syarat yaitu ada sel dengan frekuensi harapan kurang dari 5, maka rumus diganti dengan rumus Fisher Exact Test dengan nilai 1,0, karena nilai $p>0,05$ yaitu 1,0 sehingga dapat disimpulkan bahwa tidak ada hubungan antara frekuensi konsumsi pangan sumber serat dengan status gizi overweight.

Tabel 3. Hubungan Jumlah Konsumsi Pangan Sumber Serat dengan Kejadian Overweight

\begin{tabular}{|c|c|c|c|c|c|c|c|}
\hline \multirow{2}{*}{$\begin{array}{c}\text { Jumlah } \\
\text { Konsumsi } \\
\text { Pangan } \\
\text { Sumber Serat }\end{array}$} & \multicolumn{4}{|c|}{ Status Gizi } & \multicolumn{2}{|c|}{ Jumlah } & \multirow[b]{2}{*}{$\mathbf{p}^{*}$} \\
\hline & Overweight & $\%$ & Normal & $\%$ & $\mathbf{n}$ & $\%$ & \\
\hline Kurang & 12 & 30,8 & 27 & 69,2 & 39 & 100 & \multirow{3}{*}{0,819} \\
\hline Cukup & 15 & 27,8 & 39 & 72,2 & 54 & 100 & \\
\hline Total & 27 & 29 & 66 & 71 & 93 & 100 & \\
\hline
\end{tabular}

Sumber: Data primer, 2019

Berdasarkan tabel 3, untuk pembacaan analisis data jumlah konsumsi pangan sumber serat dikelompokkan menjadi 2 yaitu kurang dan cukup menunjukkan bahwa lebih banyak sampel yang memiliki status gizi overweight dengan jumlah konsumsi pangan sumber serat kurang 60 yaitu 30,8\% dibandingkan yang memiliki jumlah konsumsi pangan sumber serat cukup yaitu 27,8\%. Pada penelitian ini hasil uji chi square menunjukkan tabel kontingensi $2 \mathrm{x}$ 2 memenuhi syarat yaitu nilai expected di bawah 5 sebanyak $0 \%$ dan nilai minimum expected-nya 11,3, maka analisis p yang digunakan adalah continuity correction dengan nilai 0,189, karena nilai $p>0,05$ yaitu 0,189 sehingga dapat disimpulkan bahwa tidak ada hubungan antara jumlah konsumsi pangan sumber serat dengan status gizi overweright. 


\section{PEMBAHASAN}

Dapat disimpulkan bahwa, rata-rata frekuensi konsumsi pangan sumber serat berada pada 1-6x/minggu dan 1-3x/bln yaitu masih kurang dalam hal frekuensi dan pada jumlah konsumsi pangan sumber serat dapat disimpulkan bahwa konsumsi responden lebih banyak diatas 30-35 gr/hari. Berdasarkan hasil analisis data wawancara mendalam diketahui bahwa remaja SMP belum mengerti tentang istilah serat, sumber dan manfaatnya bagi tubuh. Frekuensi konsumsi sayur pada remaja adalah sebanyak 1-3 porsi setiap hari dan 2-3 porsi buah setiap minggu, yang berarti remaja di SMP Negeri 3 Makassar dianggap kurang mengkonsumsi makanan berserat dari 62 porsi yang seharusnya yakni sebanyak 5 porsi per hari.

Beberapa hal yang menjadi alasan remaja untuk tidak mengkonsumsi sayur dan buah adalah karena tidak tersedianya sayur dan buah di rumah, mereka tidak menyukai sayuran yang disajikan, dan tidak mood untuk makan sayur. Terdapat juga sebagian remaja lebih memilih untuk tidak mencicipi sayur karena memang tidak dibiasakan untuk mengkonsumsi sayuran oleh orangtuanya. ${ }^{7}$ Hal ini sejalan dengan penelitian Anggraerni dan Sudiarti, remaja usia 13-15 tahun memiliki konsumsi buah dan sayur lebih rendah dibanding anak usia 5-10 tahun dan usia 16 tahun ke atas. Hal lain, remaja lebih cenderung memilih makanan yang banyak mengandung lemak dan gula serta sedikit serat, vitamin, dan mineral yang berpengaruh buruk bagi kesehatan di masa selanjutnya. Hal ini yang dapat memicu terjadinya masalah gizi. ${ }^{8}$

Penelitian ini menunjukkan bahwa sampel yang memiliki status gizi overweight sebanyak 27 (29\%) dan status gizi normal sebanyak 66 (71\%). Dapat disimpulkan bahwa lebih banyak siswa yang memiliki status gizi normal dibandingkan dengan yang memiliki status gizi overweight. Hal ini dapat berpengaruh dari pola konsumsi pangan siswa yang kurang konsumsi sayur dan buah. Berdasarkan Riset Kesehatan Dasar tahun 2013, Indeks massa tubuh menurut umur (IMT/U) prevalensi remaja gemuk umur 13-15 tahun di Indonesia sebesar $10.8 \%$ terdiri dari $8,3 \%$ gemuk dan 2,5\% sangat gemuk. yang tertinggi yaitu pada provinsi kepulauan riau sebesar $0,6 \%$, provinsi DKI sebesar $0,5 \%$, prevalensi obesitas di Provinsi kalimantan timur dan Provinsi DIY sebesar 0,3\% sedangkan prevalensi obesitas Di Provinsi Sulawesi Utara dan di Provinsi Sulawesi Selatan sebesar 0,2\%. ${ }^{5}$

Analisis hubungan antara frekuensi konsumsi pangan sumber serat dengan kejadian overweight dilakukan dengan menggunakan uji chi square. Dari analisis yang dilakukan diperoleh $p=1,000$. Berdasarkan uji Fisher maka $p$ value lebih besar dari 0,05 sehingga dapat disimpulkan bahwa tidak ada hubungan signifikan antara frekuensi konsumsi pangan sumber serat dengan kejadian overweight. Hal ini sejalan dengan penelitian Vilda tahun 2016, dimana hubungan konsumsi serat dengan kejadian overweight menghasilkan $p$ value $=0,43$ yaitu tidak adanya hubungan antara konsumsi serat dengan kejadian overweight. Rendahnya asupan serat makanan seseorang dipengaruhi oleh tingkat pengetahuan seseorang tentang "serat makanan dan kesehatan", ini terutama pada anak, pengetahuan orang tua sangat berpengaruh terhadap konsumsi serat, karena anak cenderung mengikuti pola makan orang tua. ${ }^{9}$

Faktor utama penyebab overweight dan obesitas adalah aktivitas fisik yang kurang, perubahan gaya hidup, serta pola makan yang salah diantaranya pola makan tinggi lemak dan 
rendah serat. Serat memiliki peranan terhadap overweight dalam menunda pengosongan lambung, mengurangi rasa lapar, memperlancar pencernaan dan dapat membantu menurunkan berat badan. ${ }^{10}$ Analisis hubungan antara jumlah konsumsi pangan sumber serat dengan kejadian overweight dilakukan dengan menggunakan uji chi square. Dari analisis yang dilakukan pada jumlah konsumsi pangan sumber serat diperoleh $p=0,819$. Berdasarkan uji chi-square maka pvalue lebih besar dari 0,05, sehingga dapat disimpulkan bahwa tidak ada hubungan signifikan antara jumlah konsumsi pangan sumber serat dengan kejadian overweight pada remaja.

Berdasarkan hasil penelitian ini didapatkan bahwa tidak ada hubungan antara jumlah porsi konsumsi sumber serat dengan kejadian overweight. Hal ini disebabkan oleh adanya faktor lain yang memiliki hubungan dominan terhadap kejadian overweight. Setiap individu membutuhkan sejumlah zat gizi agar dapat hidup sehat dan mempertahankan hidupnya. Oleh karena itu, jumlah zat gizi yang diperoleh melalui konsumsi pangan harus mencukupi kebutuhan utnuk melakukan kegiatan, aktivitas, dan mempertahankan daya tahan tubuh. ${ }^{11}$

Hal ini sejalan dengan penelitian Inggrid (2012) yang mengatakan bahwa aktifitas fisik merupakan salah satu faktor yang mempengaruhi 68 status gizi karena status gizi seseorang bergantung juga penggunaan zat gizi yang dikonsumsi dengan cara beraktifitas. Hasil uji menggunakan korelasi spearman dengan tingkat kemaknaan mendapatkan hasil bahwa terdapat hubungan yang bermakna antara Intensitas Aktifitas Fisik dengan Status Gizi (IMT/U) dengan nilai $p=0,00 .^{12}$

Kecukupan asupan serat kini dianjurkan semakin tinggi, mengingat banyak manfaat yang menguntungkan untuk kesehatan tubuh, adequate intake (AI) untuk serat makanan sebagai acuan untuk menjaga kesehatan seluruh pencernaan dan kesehatan bagi remaja adalah 30-35 g/hari. Peran serat terhadap status gizi diantaranya menunda pengosongan lambung, mengurangi rasa lapar, pencernaan dan dapat mengurangi terjadinya gizi lebih. Kecukupan asupan serat kini dianjurkan semakin semakin tinggi, mengingat banyak manfaat yang menguntungkan untuk kesehatan. Asupan serat yang rendah dapat mengakibatkan terjadinya gizi lebih dan dapat pula mengakibatkan terjadinya penyakit degeneratif. ${ }^{13}$

\section{KESIMPULAN}

Pada penelitian ini ditemukan bahwa masih rendahnya konsumsi pangan sumber serat pada remaja. Status gizi overweight juga masih banyak ditemukan pada remaja. Pada penelitian ini dapat diketahui bahwa tidak ada hubungan antara konsumsi pangan sumber serat dengan kejadian overweight pada remaja di SMP Negeri 3 Makassar. Hal ini dapat dipengaruhi Faktor utama penyebab overweight dan obesitas yang multifactorial adalah aktivitas fisik yang kurang, perubahan gaya hidup, serta pola makan yang salah diantaranya pola makan tinggi lemak dan rendah serat. Diperlukan kesadaran bagi remaja mengenai pentingnya konsumsi sumber serat yang berasal dari penukar kabohidrat, sayuran, dan buah. Semoga penelitian ini dapat menjadi acuan yang baik untuk peneliti selanjutnya yang membahas mengenai sumber serat.

\section{DAFTAR PUSTAKA}

1. Endrika A, Christianto E, Nazriati E. Kecukupan Konsumsi Sayur Dan Buah Pada Siswa Sma Negeri 1 Kuantan Hilir. JOM FK. 2015 
2. Makaryani Y. Hubungan Konsumsi Serat Dengan Kejadian Overweight Pada Remaja Putri SMA BATIK 1 Surakarta. Naskah Publ. 2013;1-17.

3. Nurmahmudah DK, Aruben R, Suyatno. Faktor-Faktor yang Mempengaruhi Konsumsi Makan Buah dan Sayur pada Anak Pra Sekolah PAUD TK Sapta Prasetya Kota Semarang. J Kesehat Masy. 2015;3(1):244-55.

4. Mohammad A, Siti M. Konsumsi Buah dan Sayur Anak Usia Sekolah Dasar di Bogor. J Gizi Pangan. 2015;10(1):71-6.

5. Pratiwi I, Basri M. Pengaruh Senam Aerobik Terhadap Penurunan Berat Badan Remaja Obesitas di SMP Katolik Rajawali Makassar Tahun 2017. 2018;1(2):76-82.

6. Dewi E, Angkasa L, Pamungkasari EP, Dharmawan R. Effects of Fruit and Vegetable Consumption, a Socio-Economic Factor of Adolescent Obesity in Surakarta City. 2015;1172:55-64.

7. Virlita, Destriatania S, Febry F. Persepsi Kebiasaan Konsumsi Serat Pada Remaja SMP Dan SMA Kota Palembang Tahun 2013 Perception Dietary Fiber Consumption Habits In Youth Junior And Senior High School City Of Palembang In 2013. Jurnal Ilmu Kesehatan Masyarakat. 2015;6:74-82.

8. Anggraeni NA, Sudiarti T. Faktor Dominan Konsumsi Buah dan Sayur pada Remaja di SMPN 98 Jakarta. Indones J Hum Nutr. 2018;5(1):18-32.

9. Setyawati V, Rimawati E. Pola Konsumsi Fast Food dan Serat Sebagai Faktor Gizi Lebih pada Remaja. Unnes J Public Heal. 2016;5(5).

10. Susilowati, Kuspriyanto. Gizi dalam Daur Kehidupan. Bandung: PT Refika; 2016.

11. Ramadani A. Hubungan Jenis, Jumlah, dan Frekuensi Makan dengan Pola Buang Air Besar dan Keluhan Pencernaan pada Mahasiswa Muslim saat Ramadhan. 2017;

12. Ayu D, Festilia S. Hubungan Pola Makan dan Aktifitas Fisik Terhadap Status Gizi di Siswa SMP Al-Azhar Pontianak. Pontianak Nutr J. 2018;01(01).

13. Luthfia Q, Sudaryati E, Lubis Z. Asupan Zat Gizi Makro dan Serat Serta Status Gizi pada Siswa Madrasah Aliyah Negeri 1 Medan tahun 2016. 2016;1-11. 